\title{
Effects of 12-week core stabilization exercise on the Cobb angle and lumbar muscle strength of adolescents with idiopathic scoliosis
}

\author{
Kwang-Jun Ko', Seol-Jung Kang 2,* \\ 'Department of Sports Medicine, National Health Fitness Center, Seoul, Korea \\ ${ }^{2}$ Department of Physical Education, Changwon National University, Changwon, Korea
}

To identify the effects of core stabilization exercise on the Cobb angle and lumbar muscle strength of adolescent patients with idiopathic scoliosis. Subjects in the present study consisted of primary school students who were confirmed to have scoliosis on radiologic examination performed during their visit to the National Fitness Center in Seoul, Korea. Depending on whether they participated in a 12-week core stabilization exercise program, subjects were divided into the exercise $(n=14$, age $12.71 \pm 0.72$ years) or control $(n=15$, age $12.80 \pm 0.86$ years) group. The exercise group participated in three sessions of core stabilization exercise per week for 12 weeks. The Cobb angle, flexibility, and lumbar muscle strength tests were performed before and after core stabilization exercise. Repeated-measure two-way analysis of variance was performed to compare the treatment effects between the exercise and control groups. There was no significant difference in thoracic Cobb angle between the groups. The exercise group had a significant decrease in the lumbar Cobb angle after exercise compared to before exercise $(P<0.001)$. The exercise group also had a significant increase in lumbar flexor and extensor muscles strength after exercise compared to before exercise $(P<0.01$ and $P<0.001$, respectively). Core stabilization exercise can be an effective therapeutic exercise to decrease the Cobb angle and improve lumbar muscle strength in adolescents with idiopathic scoliosis.

Keywords: Idiopathic scoliosis, Core stabilization exercise, Cobb angle, Lumbar muscle strength

\section{INTRODUCTION}

Scoliosis is a disease in which the spine deviates or rotates laterally from its normal vertical line, and it can cause decreased spinal movement, weakening of muscles near the spine, reduced pulmonary function, respiratory dysfunction, chronic pain, and psychological suffering (Asher and Burton, 2006; Weinstein et al., 2003). Scoliosis can be classified as idiopathic, congenital, neurofibromatosis, and neuromuscular. Among these types of scoliosis, approximately $80 \%$ of patients with scoliosis have adolescent idiopathic scoliosis (AIS), which typically occurs around 10 years of age when healthy bone maturation occurs during adolescence. Idiopathic scoliosis (IS) is diagnosed when there are no known causes

besides spinal deformity involving a lateral curvature with a Cobb angle $\geq 10^{\circ}$ (Wick et al., 2009). In other words, because IS does not show specific symptoms, early diagnosis is often difficult; however, early detection and treatment are important since it is easy to miss the proper treatment window (Weinstein, 1989).

Treatment guidelines for IS are determined based on age, residual growth, size and condition of the curvature, and underlying diseases. In particular, there is a high probability of incurvation of the spine being progressive in adolescents; therefore, aggressive, early treatment may be able prevent further spinal deformity to a certain degree. However, if the proper treatment period is missed, cardiopulmonary dysfunction may be caused by severe curvature of the spine (Banjar, 2003). Therapeutic approaches for IS include

${ }^{*}$ Corresponding author: Seol-Jung Kang (D) http://orcid.org/0000-0002-6258-2996 Department of Physical Education, Changwon National University, 20 Changwondaehak-ro, Uichang-gu, Changwon 51149, Korea Tel : +82-55-213-3520, Fax : +82-55-266-8467, E-mail: sjkang803@hanmail.net Received: March 8, 2017 / Accepted: April 15, 2017
This is an Open Access article distributed under the terms of the Creative Commons Attribution Non-Commercial License (http://creativecommons.org/licenses/by-nc/4.0/) which permits unrestricted non-commercial use, distribution, and reproduction in any medium, provided the original work is properly cited. 
surgical and conservative treatments. Surgical treatment is considered when the Cobb angle is $\geq 40^{\circ}$, whereas conservative treatment typically involves wearing assistive devices, spinal adjustment therapy, and exercise therapy (Carman et al., 1985; Falk et al., 2015; Maruyama et al., 2011).

Exercise therapy for IS is considered important for maintaining spinal function when the Cobb angle is $<20^{\circ}$. In particular, because changes in trunk muscle strength because of IS can lead to postural imbalance, improving IS has been suggested to be important (Mcintire et al., 2007; Mooney et al., 2000). Accordingly, extension exercise for shortened muscles and resistance exercise for strengthening the muscles near the spine have been reported to be effective for IS (Negrini et al., 2003). In other words, the effects of exercise therapy for IS can be attributed to spine stabilization for muscle imbalance that occurs from asymmetric posture in the trunk.

Moreover, the effects of core stabilization exercise have been demonstrated recently for alleviating chronic lower back pain in patients, improving performance in athletes, and preventing sports injuries in athletes (Akuthota et al., 2008; Hodges, 2003; Huxel Bliven and Anderson, 2013; Kibler et al., 2006). Core stabilization exercise has been suggested as effective for increasing lumbar stability by enhancing cooperation between cocontraction of extensor and flexor muscles and neuromuscular control function (Barr et al., 2005). Based on this information, core stabilization exercise may be used effectively to increase lumbar muscle strength and improve neuromuscular imbalance, which are the causes of IS.

However, studies on the therapeutic effects of using core stabilization exercise in patients with AIS are still lacking. Accordingly, the objective of the present study was to identify the effects of core stabilization exercise on the Cobb angle and lumbar muscle strength of patients with AIS.

\section{MATERIALS AND METHODS}

\section{Subjects}

Subjects in the present study consisted of primary school students who were confirmed to have scoliosis on a radiologic exam- ination performed during their visit to the National Fitness Center in Seoul, Korea. An orthopedic specialist made the diagnosis based on a Cobb angle $\geq 10^{\circ}$. Among the primary school students who were diagnosed as having scoliosis, those with a Cobb angle $\geq 20^{\circ}$ were excluded; as a result, 29 primary school students with a Cobb angle $10^{\circ}-20^{\circ}$ who received treatments for scoliosis for the past 6 months participated in the study. Depending on whether they participated in a 12-week core stabilization exercise program, subjects were divided into the exercise $(n=14)$ or control $(n=15)$ group. An explanation of the study procedures was given to all participants, and subsequently, the voluntary decision to participate from the students and informed consent from their parents were received. Physical characteristics of the subjects are shown in Table 1.

\section{Measurement items and methods}

All tests were performed in the Sports Medicine Lab of the National Fitness Center. After measuring subjects' height and weight using a scale (Jenix, Seoul, Korea), the Cobb angle, flexibility, and lumbar muscle strength tests were performed, as explained in the following.

\section{Cobb angle test}

The Cobb angle test was performed by an orthopedic specialist by measuring the thoracic and lumbar Cobb angles on anterior and posterior spine radiographs taken in standing position. The Cobb angle was measured as the vertically intersecting angle after determining the vertebrae above the apex and below the apex, which are the most tilted from the concave side of the curvature of the spine (Deacon et al., 1984).

\section{Flexibility test}

The flexibility test was performed by having subjects bend their upper body forward. After performing sufficient stretching before the flexibility test, subjects sat on an examination table and bent their upper body forward as much as possible with their legs fully extended. This motion was performed and measured twice, and

Table 1. Physical characteristics of subjects

\begin{tabular}{lcccc}
\hline Characteristic & Exercise $(\mathrm{n}=14)$ & Control $(\mathrm{n}=15)$ & $t$ & $P$-value \\
\hline Age $(\mathrm{yr})$ & $12.71 \pm 0.72$ & $12.80 \pm 0.86$ & -0.29 & 0.773 \\
Height $(\mathrm{cm})$ & $155.37 \pm 6.90$ & $153.06 \pm 6.75$ & 0.65 & 0.524 \\
Weight $(\mathrm{kg})$ & $49.57 \pm 6.86$ & $48.44 \pm 5.50$ & 0.28 & 0.781 \\
Body mass index $\left(\mathrm{kg} / \mathrm{cm}^{2}\right)$ & $20.45 \pm 1.55$ & $20.68 \pm 2.21$ & -0.38 & 0.705 \\
\hline
\end{tabular}

Values are presented as mean \pm standard deviation. 
the maximum value from the two measurements was recorded.

\section{Lumbar muscle strength test}

The lumbar muscle strength test was performed using the Biodex 3.0 (Biodex Medical Systems, Shirley, NY, USA), an isokinetic muscle strength analyzer, to measure the muscle strength involved in lumbar flexion and extension. Before the lumbar muscle strength test, subjects were given 10 min for the stretching and warm-up exercise, and the actual test was performed after they were familiar with the lumbar flexion and extension test method. Lumbar flexor and extensor muscles were measured five times at $30 \% \mathrm{sec}$, and the maximum value from the five measurements was recorded.

\section{Core stabilization exercise program}

The exercise group participated in the spine stabilization exercise program, which consisted of three 60-min sessions per week for 12 weeks. Each exercise session consisted of a 10-min warmup exercise, 40-min core stabilization exercise, and 10-min cooldown exercise. The warm-up and cool-down exercise were comprised of 10 min of stretching and breathing exercises. The core stabilization exercise was designed with consideration of spinal adjustment and strengthening of the abdominal and lumbar muscles. All exercises were performed with supervision to ensure all exercise motions were performed accurately.

The core stabilization exercise program included pelvic tilt, cat-camel pose (back raises), basic trunk curl (crunch), bridge (with knee extension), double-leg abdominal press, supermans, $\mathrm{arm} / \mathrm{leg}$ raises, quadruped arm/leg raises, and hand walkouts. Each type of exercise was performed in 3 sets of 12 repetitions. The rating of perceived exertion was used to set the exercise intensity to somewhat difficult.

\section{Statistical analysis}

SAS (version, 9.1; SAS Institute, Cary, NC, USA) was used calculate the mean and standard deviation values for data processing in the present study. To determine inter-group mean differences, repeated-measure two-way analysis of variance was used to analyze the main and interaction effects. The significance level $(\alpha)$ was set to $P<0.05$.

\section{RESULTS}

\section{Changes in thoracic and lumbar Cobb angles}

As shown in Table 2, the thoracic Cobb angle did not have any interaction effects between groups and treatments. The lumbar Cobb angle had interaction effects between groups and treatments $(P<0.001)$. Post boc test results indicated that the exercise group had a significant decrease in the thoracic and lumbar Cobb angles from pre-exercise to postexercise $(P<0.01)$, whereas the control group did not have a significant difference in the thoracic and lumbar Cobb angles between these periods.

\section{Changes in flexibility and lumbar muscle strength}

As shown in Table 3, flexibility had significant interaction effects between groups and treatments $(P<0.001)$. Post hoc test results indicated that the exercise group had a significant increase in flexibility and lumbar muscle strength from pre-exercise to postexercise $(P<0.001)$, whereas the control group had a significant decrease in flexibility and lumbar muscle strength between these periods $(P<0.01)$.

Lumbar flexion muscles had interaction effects between groups and treatments $(P<0.001)$. Post hoc test results indicated that the exercise group had a significant increase in lumbar flexion from pre-exercise to postexercise $(P<0.01)$, whereas the control group did not have a significant difference in lumbar flexion between these periods.

Lumbar extension muscles had interaction effects between groups and treatments $(P<0.01)$. Post hoc test results indicated that the exercise group had a significant increase in lumbar extension from pre-exercise to postexercise $(P<0.001)$, whereas the

Table 2. Change in the Cobb angle before and after exercise

\begin{tabular}{|c|c|c|c|c|c|}
\hline Characteristic & Group & Pretreatment & Posttreatment & $F$ & $P$-value ${ }^{\dagger}$ \\
\hline \multirow[t]{2}{*}{ Thoracic spine $\left({ }^{\circ}\right)$} & Exercise & $14.46 \pm 2.07$ & $14.33 \pm 2.06$ & $0.49^{a} / 1.07^{b} / 0.01^{c}$ & $0.491^{\mathrm{a}} / 0.310^{\mathrm{b}} / 0.924^{\mathrm{c}}$ \\
\hline & Control & $13.93 \pm 1.96$ & $13.82 \pm 2.04$ & & \\
\hline \multirow[t]{2}{*}{ Lumbar spine $\left({ }^{\circ}\right)$} & Exercise & $15.95 \pm 1.84$ & $15.21 \pm 1.91^{* *}$ & $0.18^{a} / 18.11^{b} / 7.84^{c}$ & $0.677^{a} / 0.002^{b} / 0.093^{c}$ \\
\hline & Control & $15.36 \pm 2.07$ & $15.20 \pm 1.98$ & & \\
\hline
\end{tabular}

Values are presented as mean \pm standard deviation.

${ }^{\text {aGroup. }}{ }^{\mathrm{b}}$ Treatment. ${ }^{\circ} \mathrm{Group} \times$ treatment.

${ }^{* *} P<0.01$. ${ }^{\dagger}$ Paired $t$-test. 
Table 3. Change in the flexibility and lumbar muscle

\begin{tabular}{llcccc}
\hline Characteristic & Group & Pretreatment & Posttreatment & $F$ & $P$-value \\
\hline Flexibility $(\mathrm{cm})$ & Exercise & $12.61 \pm 6.36$ & $14.08 \pm 6.02^{* * *}$ & $1.42^{\mathrm{a}} / 17.46^{\mathrm{b}} / 24.25^{\mathrm{c}}$ & $0.244^{\mathrm{a}} / 0.001^{\mathrm{b}} / 0.001^{\mathrm{c}}$ \\
& Control & $10.74 \pm 5.91$ & $10.56 \pm 6.03^{* *}$ & & \\
Lumbar flexion muscle $(\mathrm{Nm})$ & Exercise & $188.89 \pm 22.93$ & $205.80 \pm 26.48^{* *}$ & $0.18^{\mathrm{a}} / 6.70^{\mathrm{b}} / 15.97^{\mathrm{c}}$ & $0.674^{\mathrm{a}} / 0.015^{\mathrm{b}} / 0.001^{\mathrm{c}}$ \\
& Control & $194.53 \pm 34.05$ & $190.92 \pm 34.59$ & & \\
Lumbar extension muscle $(\mathrm{Nm})$ & Exercise & $72.45 \pm 10.95$ & $86.17 \pm 9.64^{* * *}$ & $0.02^{\mathrm{a}} / 16.97^{\mathrm{b}} / 11.24^{\mathrm{c}}$ & $0.897^{\mathrm{a}} / 0.001^{\mathrm{b}} / 0.002^{\mathrm{c}}$ \\
& Control & $78.11 \pm 12.23$ & $79.52 \pm 12.35$ & & \\
\hline
\end{tabular}

Values are presented as mean \pm standard deviation.

${ }^{a}$ Group. ${ }^{b}$ Treatment. ${ }^{\circ} G r o u p \times$ treatment.

${ }^{* *} P<0.01 .{ }^{* * *} P<0.001$. ${ }^{\dagger}$ Paired $t$-test.

control group did not show a significant difference in lumbar extension between these periods.

\section{DISCUSSION}

Results of the present study showed that in the exercise group, the lumbar Cobb angle decreased, whereas flexibility and lumbar muscle strength increased.

IS refers to a disease with a Cobb angle $\geq 10^{\circ}$ that involves three-dimensional deformation, including deformation in the coronal, sagittal, and axial planes, and it occurs mostly during adolescence, which represents a growth period before and after the age of 10 years (Reamy and Slakey, 2001). If the proper treatment period for IS is missed, cardiopulmonary dysfunction may occur from severe curvature of the spine, which can also have a negative impact on patients' quality of life due to psychological and social issues (Dirocco and Vaccaro, 1988; Freidel et al., 2002). Improving the Cobb angle is key to treating IS, and in patients with progressive deformation, it is necessary to implement measures that can prevent exacerbation of the condition (Hresko, 2013). Accordingly, exercise, wearing assistive devices, and surgical therapy are being studied as alternatives for treating IS. Exercise therapy is effective in relatively mild cases with a Cobb angle ranging between $10^{\circ}$ and $20^{\circ}$ (Weiss et al., 2006).

According to a recent study, the importance of biomechanical functions of core muscles is being emphasized for their ability to stabilize the spine in terms of cooperation between deep and surface muscles (Hibbs et al., 2008). Accordingly, core stabilization exercise is effective for controlling one's movements to maintain a neutral position of the spine, which is why it is widely used for patients with lower back pain, athletes, and healthy people (Barr et al., 2005). Results in the present study showed a decrease in the thoracic Cobb angle after core stabilization exercise, but the differences were not significant. However, the lumbar Cobb angle did significantly decrease. Similar to the present study, Gür et al. (2016) reported that a 10-week core stabilization exercise program decreased thoracic and lumbar Cobb angles in primary school students with scoliosis. Park et al. (2016) also reported that a 10-week core stabilization exercise program for college students with scoliosis decreased their Cobb angle. Other precedent studies also reported that core stabilization exercise alleviated thoracic kyphosis and lumbar lordosis in the sagittal plane of the spine and effectively improved spinal alignment (Hirano et al., 2012; Katzman et al., 2007). Therefore, core stabilization exercise can be viewed as a useful treatment modality for reducing the Cobb angle in patients with AIS.

Moreover, IS can induce changes in muscles near the spine, and in particular, weakening of the lumbar muscle strength can cause spinal instability. Consequently, it is important to provide stability to the spine while increasing lumbar muscle strength. Regarding core stabilization exercise, cooperative contraction of lumbar flexion and extension muscles plays an important role in spinal stability (Akuthota and Nadler, 2004; Lederman, 2010). Results of the present study showed that flexibility, and lumbar flexion and extension muscle strength increased significantly after core stabilization exercise. These findings are consistent with the results of precedent studies that reported that lumbar stabilization exercise increases lumbar and truncal muscle strength in patients with lower back pain (Moon et al., 2013; Yílmaz et al., 2003). As our results indicated, core stabilization exercise is effective for improving lumbar range of motion and muscle strength in patients with IS. This can be attributed to the fact that core stabilization exercise plays a role in enhancing muscle functions from co-contraction of deep muscles and cooperation of surface muscles.

Consequently, core stabilization exercise can be considered to have a positive effect on the normal physiological curvature of the spine in patients with AIS, as it decreases the Cobb angle and strengthens lumbar muscles. Therefore, core stabilization exercise 
can be an effective treatment modality for patients with who have asymmetric spine alignment.

In conclusion, the present study's results showed that in the exercise group, the lumbar Cobb angle decreased and lumbar muscle strength increased. Therefore, core stabilization exercise is an effective exercise for reducing the Cobb angle and improving lumbar muscle strength in patients with AIS.

\section{CONFLICT OF INTEREST}

No potential conflict of interest relevant to this article was reported.

\section{REFERENCES}

Akuthota V, Ferreiro A, Moore T, Fredericson M. Core stability exercise principles. Curr Sports Med Rep 2008;7:39-44.

Akuthota V, Nadler SF. Core strengthening. Arch Phys Med Rehabil 2004;85(3 Suppl 1):S86-92.

Asher MA, Burton DC. Adolescent idiopathic scoliosis: natural history and long term treatment effects. Scoliosis 2006;1:2.

Banjar HH. Pediatric scoliosis and the lung. Saudi Med J 2003;24:957-963.

Barr KP, Griggs M, Cadby T. Lumbar stabilization: core concepts and current literature, Part 1. Am J Phys Med Rehabil 2005;84:473-480.

Carman D, Roach JW, Speck G, Wenger DR, Herring JA. Role of exercises in the Milwaukee brace treatment of scoliosis. J Pediatr Orthop 1985;5: 65-68.

Deacon P, Flood BM, Dickson RA. Idiopathic scoliosis in three dimensions. A radiographic and morphometric analysis. J Bone Joint Surg Br 1984;66:509-512.

DiRocco PJ, Vaccaro P. Cardiopulmonary functioning in adolescent patients with mild idiopathic scoliosis. Arch Phys Med Rehabil 1988;69(3 Pt 1):198-201.

Falk B, Rigby WA, Akseer N. Adolescent idiopathic scoliosis: the possible harm of bracing and the likely benefit of exercise. Spine J 2015;15:209210.

Freidel K, Petermann F, Reichel D, Steiner A, Warschburger P, Weiss HR. Quality of life in women with idiopathic scoliosis. Spine (Phila Pa 1976) 2002;27:E87-91.

Gür G, Ayhan C, Yakut Y. The effectiveness of core stabilization exercise in adolescent idiopathic scoliosis: A randomized controlled trial. Prosthet Orthot Int 2016 Sep 13 [Epub]. pii: 0309364616664151.

Hibbs AE, Thompson KG, French D, Wrigley A, Spears I. Optimizing performance by improving core stability and core strength. Sports Med 2008;38:995-1008.
Hirano K, Imagama S, Hasegawa Y, Wakao N, Muramoto A, Ishiguro N. Effect of back muscle strength and sagittal spinal imbalance on locomotive syndrome in Japanese men. Orthopedics 2012;35:e1073-1078.

Hodges PW. Core stability exercise in chronic low back pain. Orthop Clin North Am 2003;34:245-254.

Hresko MT. Clinical practice. Idiopathic scoliosis in adolescents. N Engl J Med 2013;368:834-841.

Huxel Bliven KC, Anderson BE. Core stability training for injury prevention. Sports Health 2013;5:514-522.

Katzman WB, Sellmeyer DE, Stewart AL, Wanek L, Hamel KA. Changes in flexed posture, musculoskeletal impairments, and physical performance after group exercise in community-dwelling older women. Arch Phys Med Rehabil 2007;88:192-199.

Kibler WB, Press J, Sciascia A. The role of core stability in athletic function. Sports Med 2006;36:189-198.

Lederman E. The myth of core stability. J Bodyw Mov Ther 2010;14:84-98.

Maruyama T, Grivas TB, Kaspiris A. Effectiveness and outcomes of brace treatment: a systematic review. Physiother Theory Pract 2011;27:26-42.

McIntire KL, Asher MA, Burton DC, Liu W. Trunk rotational strength asymmetry in adolescents with idiopathic scoliosis: an observational study. Scoliosis 2007;2:9.

Moon HJ, Choi KH, Kim DH, Kim HJ, Cho YK, Lee KH, Kim JH, Choi YJ. Effect of lumbar stabilization and dynamic lumbar strengthening exercises in patients with chronic low back pain. Ann Rehabil Med 2013; 37:110-117.

Mooney V, Gulick J, Pozos R. A preliminary report on the effect of measured strength training in adolescent idiopathic scoliosis. J Spinal Disord 2000;13:102-107.

Negrini S, Antonini G, Carabalona R, Minozzi S. Physical exercises as a treatment for adolescent idiopathic scoliosis. A systematic review. Pediatr Rehabil 2003;6:227-235.

Park YH, Park YS, Lee YT, Shin HS, Oh MK, Hong J, Lee KY. The effect of a core exercise program on Cobb angle and back muscle activity in male students with functional scoliosis: a prospective, randomized, parallel-group, comparative study. J Int Med Res 2016;44:728-734.

Reamy BV, Slakey JB. Adolescent idiopathic scoliosis: review and current concepts. Am Fam Physician 2001;64:111-116.

Weinstein SL. Adolescent idiopathic scoliosis: prevalence and natural history. Instr Course Lect 1989;38:115-128.

Weinstein SL, Dolan LA, Spratt KF, Peterson KK, Spoonamore MJ, Ponseti IV. Health and function of patients with untreated idiopathic scoliosis: a 50-year natural history study. JAMA 2003;289:559-567.

Weiss HR, Negrini S, Rigo M, Kotwicki T, Hawes MC, Grivas TB, Maruyama T, Landauer F; (SOSORT guideline committee). Indications for conservative management of scoliosis (guidelines). Scoliosis 
2006;1:5.

Wick JM, Konze J, Alexander K, Sweeney C. Infantile and juvenile scoliosis: the crooked path to diagnosis and treatment. AORN J 2009;90:347-

376.
Yílmaz F, Yílmaz A, Merdol F, Parlar D, Sahin F, Kuran B. Efficacy of dynamic lumbar stabilization exercise in lumbar microdiscectomy. J Rehabil Med 2003;35:163-167. 